\begin{tabular}{|c|c|}
\hline Title & $\begin{array}{l}\text { Impact of anthropogenic disturbance on the density and activity pattern of deer evaluated with respect to spatial scale } \\
\text { dependency }\end{array}$ \\
\hline Author(s) & A getsuma, Naoki; Koda, Ryosuke; T sujino, Riyou; A getsuma Y anagihara, Y oshimi \\
\hline Citation & $\begin{array}{l}\text { Mammalian Biology - Zeitschrift für Säugetierkunde, 81(2), 130-137 } \\
\text { https://doi.org/10.1016/.mambio.2015.09.005 }\end{array}$ \\
\hline Issue Date & $2016-03$ \\
\hline Doc URL & http:/hdl .handle.net/2115/64625 \\
\hline Rights & $\begin{array}{l}\text { @ 2016. This manuscript version is made available under the CC-BY-NC-ND } 4.0 \text { license } \\
\text { http://creativecommons.org/icenses/by-nc-nd/4.0/ }\end{array}$ \\
\hline Rights(URL) & http://creativecommons.org/icenses/by-nc-nd/4.0/ \\
\hline Type & article (author version) \\
\hline File Information & DisturbDeer.pdf \\
\hline
\end{tabular}

Instructions for use 
Original Investigation

\title{
Impact of anthropogenic disturbance on the density and activity pattern of deer evaluated with respect to spatial scale-dependency
}

Naoki Agetsuma ${ }^{a}$, Ryosuke Kodab ${ }^{b}$ Riyou Tsujino ${ }^{c}$, Yoshimi Agetsuma-Yanagiharad

\author{
a Wakayama Experimental Forest, Hokkaido University, Kozagawa, Japan \\ b Research Institute of Environment, Agriculture and Fisheries, Habikino, Osaka Prefecture, Japan \\ c Center for Natural Environment Education, Nara University of Education, Nara, Japan \\ d Hirai 343-1, Kozagawa, Wakayama 649-4563, Japan
}

\begin{abstract}
This study examined the influence of anthropogenic disturbance (agriculture, forestry, hunting and feral domestic dogs) on the population density and daily activity pattern of deer. We quantified the effects of land use (broad-leaved forest, mixed coniferous/broad-leaved forest, natural grassland, subalpine vegetation, forestry area, and agricultural land), along with hunting pressure, and densities of feral domestic dogs and wild macaques on deer. The effects of land use were analyzed at various spatial scales and a model selection procedure (generalized mixed model) was used to examine the effects of factors on density and daily activity pattern of deer at each spatial scale. The combinations of influential factors differed between density and daily activity pattern and changed with spatial scale. The spatial scale with the smallest Akaike's Information Criterion value was defined as the effective spatial scale for each of density and daily activity pattern. Deer density was affected positively by the percentage of area covered by broad-leaved forest, natural grassland and macaque density, and negatively by percentage of area covered by agricultural land and mixed forest at the effective spatial scales. For the daily activity pattern of deer, agricultural land, forestry area, natural grassland, subalpine vegetation and dog density reduced diurnal and increased nocturnal activity. Crepuscular activity increased with hunting pressure and subalpine vegetation, and decreased with agricultural land. Thus, daily activity pattern was sensitive to more types of anthropogenic disturbance than density. Detecting the appropriate spatial scales at which significant anthropogenic disturbance should be managed is essential for effective wildlife conservation.
\end{abstract}

Keywords: Cervus nippon yakushimae, Hunting pressure, Land use, Macaque, Spatial scale

\section{Introduction}

Anthropogenic disturbance influences wildlife populations worldwide (Baillie et al., 2004) altering various aspects of their ecology, which may include population density (e.g., 
Blom et al., 2004; Hockin et al., 1992; Silva-Rodriguez and Sieving, 2012), activity pattern (e.g., Kilpatrick and Lima, 1999; Presley et al., 2009), habitat use (e.g., Coulon et al., 2008; Fletcher and Hutto, 2008; Hockin et al.,1992; Markovchick-Nicholls et al., 2008), reproductive success and energy budget (Hockin et al., 1992), depending on the type and magnitude of disturbance. A single type of disturbance may affect multiple aspects of wildlife ecology (Gill et al., 2001; Kilgo et al., 1998). Anthropogenic disturbance influences wildlife in complex ways, and may have both negative and positive effects (e.g., Fletcher and Hutto, 2008; Markovchick-Nicholls et al., 2008).

Habitat transformation is a major factor affecting wild populations by altering the availability of resources, including food and shelter sites. Examples of species whose populations have increased in response to such disturbance include raccoons (Procyon lotor), whose density has increased in urban and suburban areas (Riley et al., 1998) following considerable habitat modifications, and some species of New World fruit bats (Phyllostomidae), which are more abundant in farmland or secondary forests than in primary forests (Willig et al., 2007). However, in most cases the effects of habitat transformation on wildlife populations are negative. For example, the density of the Japanese macaque (Macaca fuscata) decreases in areas with coniferous plantations (Agetsuma et al., 2015; Hill et al., 1994) and ungulates may avoid artificially exposed areas without shelter sites (Mysterud and Ostbye, 1999).

Hunting and control measures also alter the population density, activity pattern and habitat use of some wildlife species. For example, white-tailed deer (Odocoileus virginianus) exhibited significant shifts in core area use and daily activity pattern between the pre-hunt and hunt periods (Kilpatrick and Lima, 1999). In addition, domestic dogs (Canis familiaris) induce alert and flight behaviors in some wildlife species (Hockin et al., 1992; Miller et al., 2001; Sweeney et al., 1971), and may decrease the population density of certain species (SilvaRodriguez and Sieving, 2012).

To evaluate the effects of anthropogenic disturbance on wildlife populations, we should consider the extent of the effects across space, because the magnitude of the effects of disturbance on wildlife may vary with spatial scale (Coulon et al., 2008), and then responses of wildlife to anthropogenic disturbance and natural factors may depend on spatial scales (Anderson et al., 2005). Many studies have selected the spatial scales for analysis (buffer sizes) by referring to some ecological factor, such as the range size of individual animals (e.g., Boyce et al., 2003; Fletcher and Hutto, 2008; Zweifel-Schielly et al., 2009). However, we cannot accurately identify ecologically meaningful scales a priori (Zweifel-Schielly et al., 2009). Ideally, we should use the spatial scale at which the factors show the most significant effects on wildlife populations for analysis, otherwise significant factors may not be detected. Furthermore, for wildlife conservation, we should manage significant anthropogenic disturbances at the effective spatial scale.

This study examined the effects of anthropogenic disturbance on population density and daily activity pattern of Japanese sika deer (Cervus nippon). Forestry areas, agricultural land, hunting pressure and feral domestic dogs were regarded as forms of anthropogenic disturbance, and we quantified the effects of these factors, as well as those of natural factors. 
We analyzed the effects of land use at various spatial scales to determine the effective spatial scale. We then made three predictions concerning anthropogenic disturbance. Prediction 1: deer density will be negatively affected by forestry areas, hunting pressure and dog density, and positively affected by agricultural land. This is based on findings that the availability of natural resources for deer is much reduced in coniferous plantations (Agetsuma, 2007; Gill et al., 1996), that hunting and dogs can directly and indirectly decrease deer numbers, respectively (Kilpatrick and Lima, 1999; Silva-Rodriguez and Sieving, 2012), while agricultural crops may attract deer. Prediction 2: hunting pressure, agricultural land and forestry area will modify the daily activity pattern of deer because human activity is likely to restrict diurnal activity of the deer (Mysterud and Ostbye, 1999). As a result, diurnal activity will decrease, while crepuscular and nocturnal activity will increase under these types of disturbance. In addition, dog density also will modify the daily activity pattern of deer, because the presence of predators may influence deer activity (Kamler et al., 2007). Prediction 3: at the effective spatial scale, influential factors will differ between deer density and daily activity pattern because density and activity may be modified through different mechanisms.

\section{Material and methods}

\section{Study area and subjects}

Yakushima is a roughly circular, mountainous island (peak elevation $1936 \mathrm{~m}$ ) of 505 $\mathrm{km}^{2}$ located in Kagoshima Prefecture, southern Japan (30॰N, 130॰E). Approximately 13,500 residents live in more than 20 villages around the coast. Most of the settled areas are at less than $100 \mathrm{~m}$ above sea level (a.s.l.). Agricultural fields including orange orchards, rice paddies, vegetable fields and pastures lie below approximately $200 \mathrm{~m}$ a.s.l. The natural vegetation shows zonation (Fig. 1) with elevation (Ohsawa et al., 2006; Tagawa, 1994). Below approximately $800 \mathrm{~m}$ a.s.l. the predominant vegetation is evergreen broad-leaved forest, which was extensively logged from the 1960s to 1970s. Following logging, many areas were replanted with coniferous trees (Cryptomeria japonica) (Agetsuma, 2007). Mixed forests including coniferous, and evergreen and deciduous broad-leaved trees dominate the area from approximately 800 to $1700 \mathrm{~m}$ a.s.l. In the subalpine region (above1800 $\mathrm{m}$ a.s.l.), vegetation is mainly comprised of rhododendron shrubs (Rhododendron yakushimanum) and dwarf bamboo (Pseudosasa owatarii) grasslands.

The annual precipitation ranges from 2500 to $8700 \mathrm{~mm}$ across the island depending on location (Environment Agency, 1984). Along the coast, the annual mean temperature is approximately $20{ }^{\circ} \mathrm{C}$, which corresponds to the margin between subtropical and warm temperate zones (Tagawa, 1994). However, above $1000 \mathrm{~m}$ a.s.l., the climate is much cooler, with snowfall in winter and a mean annual temperature of approximately $10{ }^{\circ} \mathrm{C}$ (Ohsawa et al., 2006).

The subject of this study was a subspecies of the Japanese sika deer (Cervus nippon yakushimae) that is endemic to Yakushima and Kuchinoerabujima, an island of $36 \mathrm{~km}^{2}$ located $12 \mathrm{~km}$ northwest of Yakushima. C. n. yakushimae has the smallest body size of all subspecies of Japanese sika deer (Izawa et al., 1996). Habitat modification by logging and 
replacement with coniferous plantations caused the deer population to decline greatly from the 1960s to1970s. However, it has been recovering since the 1990s (Agetsuma, 2007) and the population size was estimated to be around 17,000 in 2008 (Koda et al., 2010). The deer inhabit most regions of the island, ranging from the coast to the subalpine zone. However, population density varies considerably with location (Agetsuma, 2007; Koda et al., 2011).

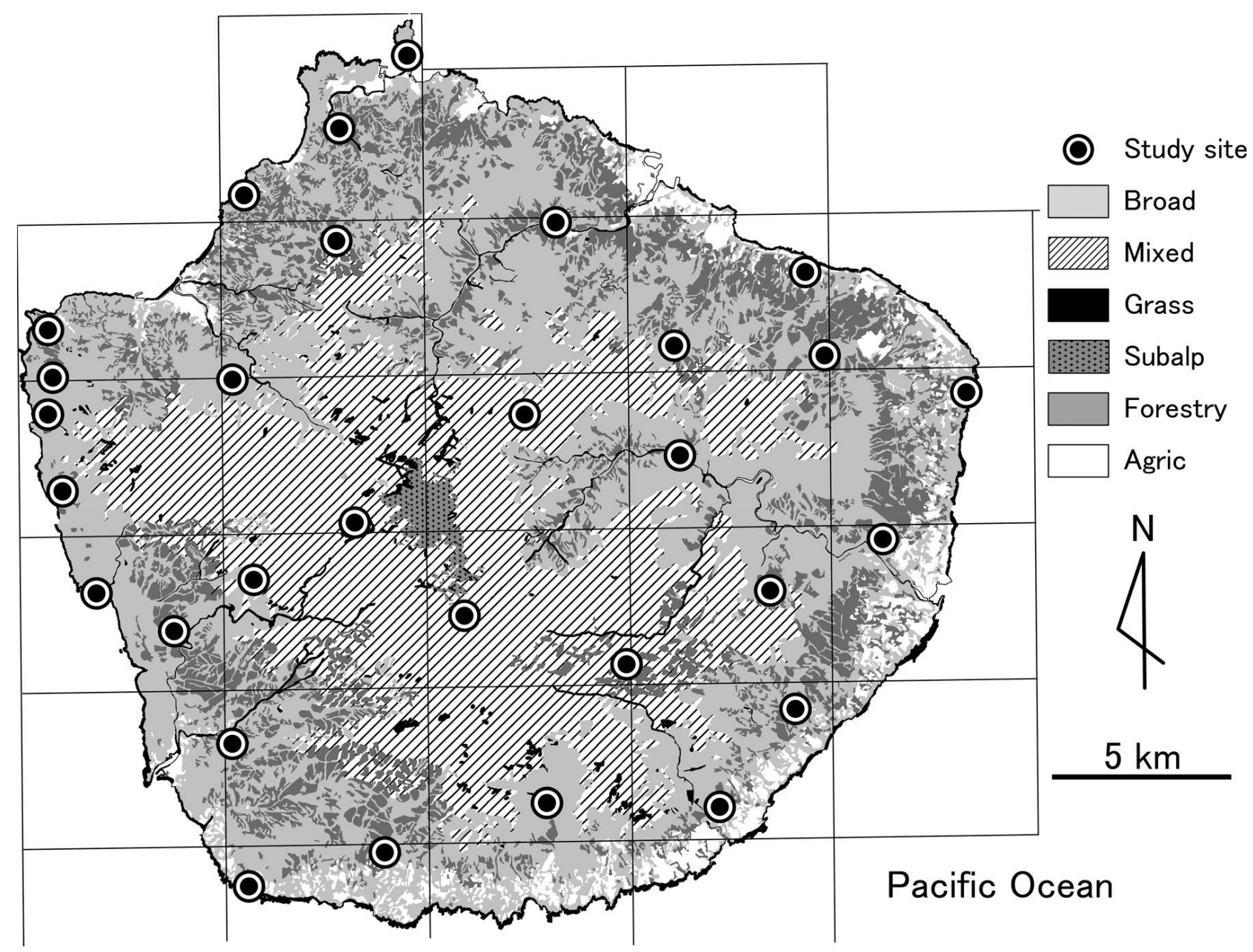

Fig. 1. Land use and study sites on the island of Yakushima. Symbols for study sites indicate gravity points of analyzed camera locations at the sites. Broad, broad-leaved forest, Mixed, mixed coniferous/broad-leaved forest; Grass, natural grassland; Subalp, subalpine vegetation; Forestry, forestry area; Agric, agricultural land. Natural grassland occurred in very narrow strips near the coast, rivers and cliffs. The number of hunted deer was summarized using cells of about $4.6 \mathrm{~km} \times 6 \mathrm{~km}$ shown on this map.

Leaves, fruits and seeds of woody plants make up the typical staple diet of the deer (Takatsuki, 1990). These foods are obtained largely from the forest litter (Agetsuma et al., 2011). The deer also feed on food dropped from trees by Japanese macaques (Macaca fuscata yakui) that also inhabit most regions of the island. Food obtained in this way accounts for $7 \%$ of time spent feeding by deer in broad-leaved forest (Agetsuma et al., 2011). Because the foods dropped by the macaques from the trees are relatively high quality foods (fruits and seeds) compared with other foods (Agetsuma et al., 2011), the presence of macaques attracts deer in 
the forest (Koda, 2012). A previous study showed that the density of macaques was positively affected by broad-leaved forest area and negatively by forestry area within a radius of $400 \mathrm{~m}$ (Agetsuma et al., 2015).

The mean annual range size of an individual of deer in a broad-leaved forest, expressed as a $90 \%$ fixed kernel, is 12 ha $(7-17$ ha, $\mathrm{n}=4)$ for adult females and 36 ha (4-78 ha, $\mathrm{n}=4$ ) for adult males (Agetsuma et al., 2005). The deer have very stable ranges which last for years, however, some adult males occasionally emigrate 4-8 km from their former ranges regardless of the season (Agetsuma et al., 2005; Agetsuma et al., unpublished data).

The only wild carnivores in Yakushima are a small weasel (Mustela itatsi sho), which is native, and the raccoon dog (Nyctereutes procyonoides), which was introduced to the island around1990 (Tsujino and Agetsuma-Yanagihara, 2006). So the deer have no natural predators, although feral domestic dogs ( $C$. familiaris) also inhabit the island, and local people and researchers (Tsujino and Agetsuma-Yanagihara, 2006) have observed predation of deer by both solitary individuals and groups of feral dogs.

Although deer damage crops and planted trees, the amount of damage appears to have stabilized since 1990 (Agetsuma, 2007). Deer hunting has been traditionally conducted in Yakushima, and in addition, pest control of deer started in 1978 (Agetsuma, 2007). Since 1998, hunting and controlling have only been permitted around agricultural lands. Therefore, the hunting pressure is high in agricultural areas and declines with distance from them. By 2009, local people were culling around 250-500 deer for hunting and pest control every year (data from Kagoshima Prefecture).

\section{Density of wildlife and activity pattern}

Field surveys were conducted during periods when there is no snow cover (from November to December 2007, from February to June and from November to December 2008) at 30 sites across the island that were chosen to represent various types of land use and topographies (Fig. 1). The mean minimum interval between sites was $2.7 \mathrm{~km}$ (range: $0.5-4.5$ $\mathrm{km}$ ). We surveyed the density and daily activity pattern of deer, macaques and dogs using automatic cameras with infrared sensors that could detect animal movement, as used in a previous study (Okabe and Agetsuma, 2007). At each site, 11-15 cameras (Yoyshot, Umezawa Musen Denki Co. Ltd., Sapporo, Japan) were set arbitrarily at 100 m intervals for approximately one month. We recorded the locations of these cameras using Global Positioning System receivers (GPSmap 60CSx, Garmin Ltd., Olathe, KS, USA). We loaded each camera with a 36-exposure film and fixed it $\sim 1.4 \mathrm{~m}$ above the ground. The camera's flash was set in poor lighting conditions and the lens was pointed downward at an angle of $\sim 30$ 。 toward the ground surface (Okabe and Agetsuma, 2007). Each camera could photograph animals entering an area of approximately $15 \mathrm{~m}^{2}$. The date and time were superimposed on each photograph. Some cameras were damaged by wind and rain, but data were obtained from 8 to 15 cameras at each site (403 cameras in total). The mean area of the minimum convex polygons surrounding the camera locations at each site was 21 ha.

We identified the species of photographed animals and counted them. Where there were more than one image of the same individual (as identified by sex, body size, fur color, 
antler shape and other physical characteristics) taken within $1 \mathrm{~h}$ by the same camera, only one was counted to prevent repetitive photographing of the same individual during a single visit to the camera. We then counted the number of deer, macaques and dogs in the photographs. Because the cameras did not always function for the complete duration of the study, either as a result of malfunction or completion of the film roll, we determined the number of hours that each camera was functioning from date and time stamps on the photographs, and the operating condition of the camera when collected.

The rate at which animals are photographed by automatic cameras can be used as an index of the population density (e.g., Rovero and Marshall, 2009). The photographic rate for each camera was calculated by dividing the number of photographed animals by the number of days $(24 \mathrm{~h}$ ) for which the camera operated. Then the density index of each species at each site was obtained by averaging the photographic rates for cameras at each site. The density index of macaques and dogs at each site was assigned to each camera location within the same site (Table 1).

We assessed the daily activity pattern of animals by counting the number of animals photographed by each camera during daytime (08:00-16:00), nighttime (20:00-04:00), and crepuscular periods(04:00-08:00 and 16:00-20:00).

\section{Land use}

To analyze land use on Yakushima, we used data from the 6th and 7th National Surveys of the Natural Environment conducted in 2004 by the Biodiversity Center of Japan, Ministry of the Environment. The data were generated by analyzing aerial photographs and provided in shape files that could be manipulated in a Geographic Information System (GIS). The spatial resolution was approximately $20 \mathrm{~m}$, which was sufficient for this study. We classified the land use of the island into six types (Fig. 1): (1) broad-leaved forest; (2) mixed coniferous/broad-leaved forest; (3) natural grass-land (mainly riverside, coastal and cliff vegetation); (4) subalpine vegetation (dwarf bamboo and rhododendron shrubs); (5) forestry area (coniferous plantations and logged areas); (6) agricultural land(orchards, rice paddies, vegetable fields, pastures, previously-used arable land and human residential areas).

Buffer zones were created within a radius of $200 \mathrm{~m}$ of each camera using ArcGIS (ver. 9.3, ESRI, Redlands, CA, USA). Then we calculated the percentage of total land area covered by each land use type within each buffer zone. We repeated this procedure, increasing the radius of the buffer at 50-m intervals from $250 \mathrm{~m}$ up to $1500 \mathrm{~m}$. These buffers were then used to determine the spatial scale at which the deer density and daily activity pattern were most affected. The mean terrestrial area of buffer zones with $200 \mathrm{~m}$ radius was $12.4 \mathrm{ha}$, which is approximately equal to the mean annual range of a female deer.

Some climatic factors such as temperature, precipitation and wind strength may affect deer density and activity patterns. In Yakushima, variations in elevation influence both climatic factors (i.e. higher elevations tend to have lower temperatures and greater amounts of precipitation), as well as vegetation zonation (Ohsawa et al., 2006; Tagawa, 1994). Therefore, in this study, we considered that climatic factors could be reflected in the differing types of natural vegetation in the land use types (1-4), described above. 


\section{Hunting pressure}

Kagoshima Prefecture summarized the number of deer hunted from 2006 to 2008 using a systematic grid system, with cells of about $4.6 \mathrm{~km} \times 6 \mathrm{~km}$ (Fig. 1). Because the cells included water bodies, total land area varied between cells. Therefore, we estimated hunting pressure for each cell by dividing the number of deer hunted in each cell by the total land area. For each study site hunting pressure was determined by that of the cell in which the site was located, and the same hunting pressure value was attributed to every camera at that site. When a study site included parts of two adjacent cells, we calculated the hunting pressure as the mean hunting pressure of the two cells. Hunting pressure was only evaluated at one spatial scale, and the spatial resolution was lower than that of land use.

\section{Statistical analyses}

Statistical analyses were performed using the $\mathrm{R}$ statistical computing environment, version 3.2.0 (R Core Team, 2015). To quantify the factors affecting deer density and daily activity pattern (diurnal, crepuscular and nocturnal activities) we used generalized linear mixed models (GLMM). For multivariate analyses, including GLMM, multicollinearity among explanatory variables needs to be resolved in advance. Because high multicollinearity among the nine explanatory variables was expected, we created two explanatory variable groups each including eight of the nine variables (broad-leaved forest and mixed forest were each excluded from one group; see Table 1). We checked the variance inflation factors (VIF) and correlation coefficients $(\mathrm{r})$ between all variables in the two variable groups at each spatial scale. From scales of $200 \mathrm{~m}$ to $1500 \mathrm{~m}$, VIF remained less than 4.0 and absolute values of $\mathrm{r}$ were less than 0.7 within each variable group. As the degree of the multicollinearity was acceptable (Dormann et al., 2013; Sergent et al., 1995) using the two variable groups up to the 1500 - $\mathrm{m}$ scale, we focused on these spatial scales for further analyses. The $1500 \mathrm{~m}$ radius buffer from each camera was quite large (on average 616 ha excluding areas of sea and rivers) in relation to the annual range size of most deer.

GLMMs were created using the "glmmadmb" function in the glmmADMB package of R (Skaug et al., 2014). For the analysis of deer density, we set the number of deer photographed by each camera as a response variable, the two groups of variables alternately as explanatory variables, and the log-transformed number of days the camera operated as an offset term at each spatial scale (Table 1). As data were collected from multiple cameras at each site, there was a risk of pseudoreplication (Hurlbert, 1984). To control for this the study site at which the camera was located was set as a random effect term on the intercept in the GLMM. For the analysis of daily activity pattern, we set the number of deer photographed during each time window as a response variable (Table 1). Then we set the two groups of variables alternately as explanatory variables, the log-transformed total number of deer photographed by each camera as an offset term, and the study site as a random effect term on the intercept. We assumed that the response variables follow a negative binomial distribution with a log link function for GLMM. 
Table 1

Information of response variables, explanatory variables, offset terms and a random effect term for the negative binomial generalized linear mixed models.

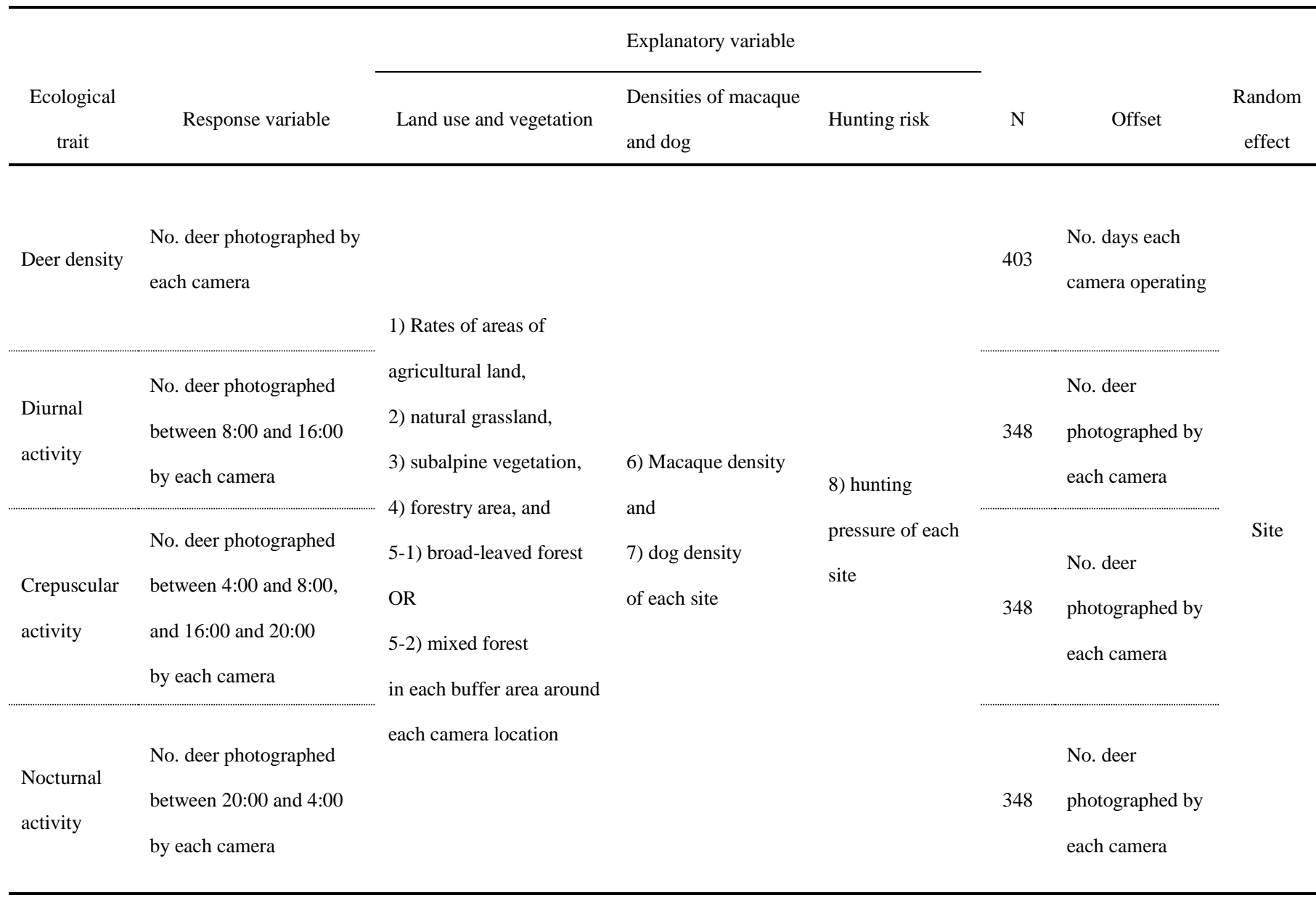

First, we made 384 models with all possible combinations of variables, including the null model, at each spatial scale for deer density and daily activity pattern, and calculated Akaike's Information Criterion (AIC) of the models. Then a $95 \%$ confidence set of models was identified by cumulatively summing the Akaike weights from highest to lowest until $\geq 0.95$ (Burnham and Anderson, 2002) using the "model.sel" and "model.avg" functions in the MuMIn package of $\mathrm{R}$ (Barton, 2015). We calculated confidence intervals for each modelaveraged coefficient of variable using unconditional standard errors of the coefficient. We excluded variables having $85 \%$ confidence intervals of the coefficients including zero as uninformative variables (Arnold, 2010). Next, we selected models among possible combinations of variables without the uninformative variables at each spatial scale. We selected variables included in the models with $\Delta \mathrm{AIC}<2$ at each spatial scale. To test the significance of the model with the smallest AIC value at each spatial scale, a likelihood ratio test to the null model was performed using the "anova" function in the glmmADMB package.

We assumed that the smallest AIC value found among the models at each spatial scale represented the effectiveness of the scale for explaining deer density and activity pattern. We identified the points at which the AIC values dipped as the effective spatial scales. At the effective spatial scales, we selected models having $\Delta \mathrm{AIC}<2$. 


\section{Results \\ Deer density}

The mean number of cameras used for wildlife density estimation was 13.4 per site (total 403 cameras) and the mean operating period of each camera was $503.7 \mathrm{~h}$ (20.9 days). We obtained 3322 images of deer, 1046 of macaques and 65 of dogs for density estimations. The mean deer density varied widely between sites and the maximum was 19.5 times the minimum. Even between the two closest sites, which were $0.5 \mathrm{~km}$ apart, there was a difference of 9.5 times in mean deer density.

For all spatial scales, the models with the smallest AIC were highly significantly different from the null model (likelihood ratio test, for all spatial scales, $\mathrm{p}<0.0001$ ). In total, six factors were selected across the scales for deer density (Fig. 2A). Combinations of the selected factors changed with spatial scale, although macaque density was consistently selected. The AIC value was smallest at the $250-\mathrm{m}$ scale, and a dip of AIC was also observed at the $600-\mathrm{m}$ scale, so these were identified as the effective spatial scales for deer density. At both of these scales, broad-leaved forest and macaque density were positive factors and agricultural land was a negative factor affecting deer density (Table 2). In addition, mixed coniferous/broad-leaved forest was a negative factor at a scale of $250 \mathrm{~m}$ and natural grassland was a positive factor at a scale of $600 \mathrm{~m}$. The mean buffer areas at the spatial scales of $250 \mathrm{~m}$ and $600 \mathrm{~m}$, excluding sea and rivers, were 19.2 ha and $105.8 \mathrm{ha}$, respectively.

Among the models without macaque density in the explanatory variables, the smallest AIC model also appeared at the 250-m scale (AIC: 2550.6, likelihood ratio test to the null model; $p<0.001$ ) and included agricultural land as a negative factor and broad-leaved forest as a positive factor affecting deer density. However, the model had a significantly lower likelihood than the model including macaque density (likelihood ratio test: $\mathrm{p}<0.001$ ). 


\section{A. Deer density}

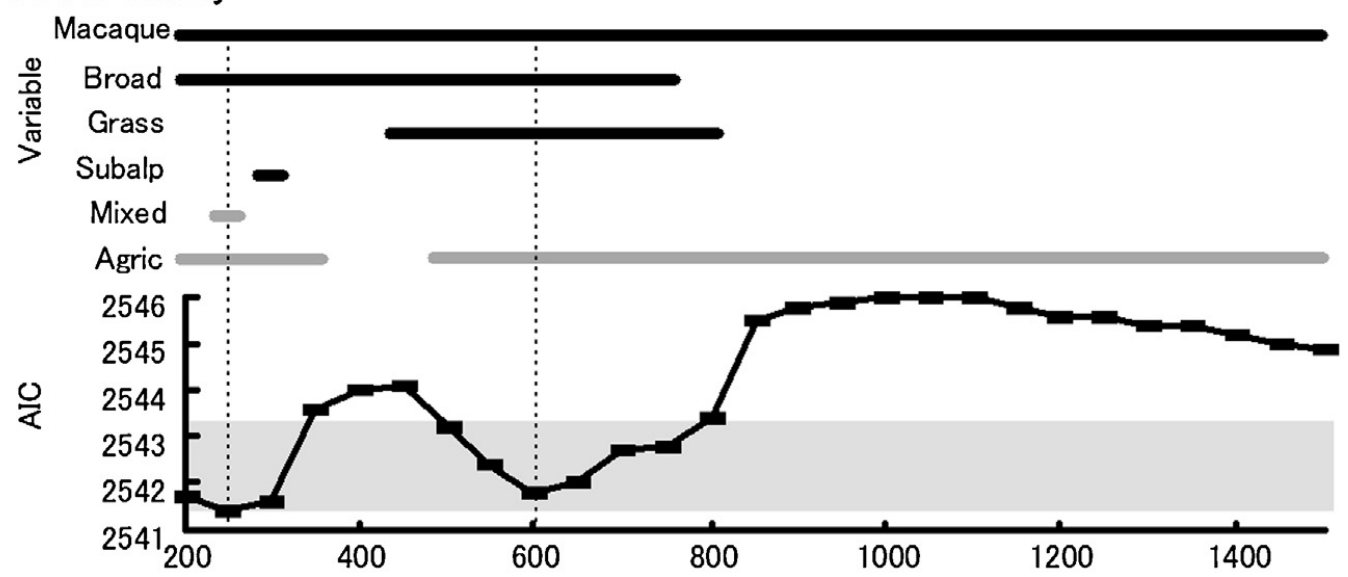

B. Diurnal activity

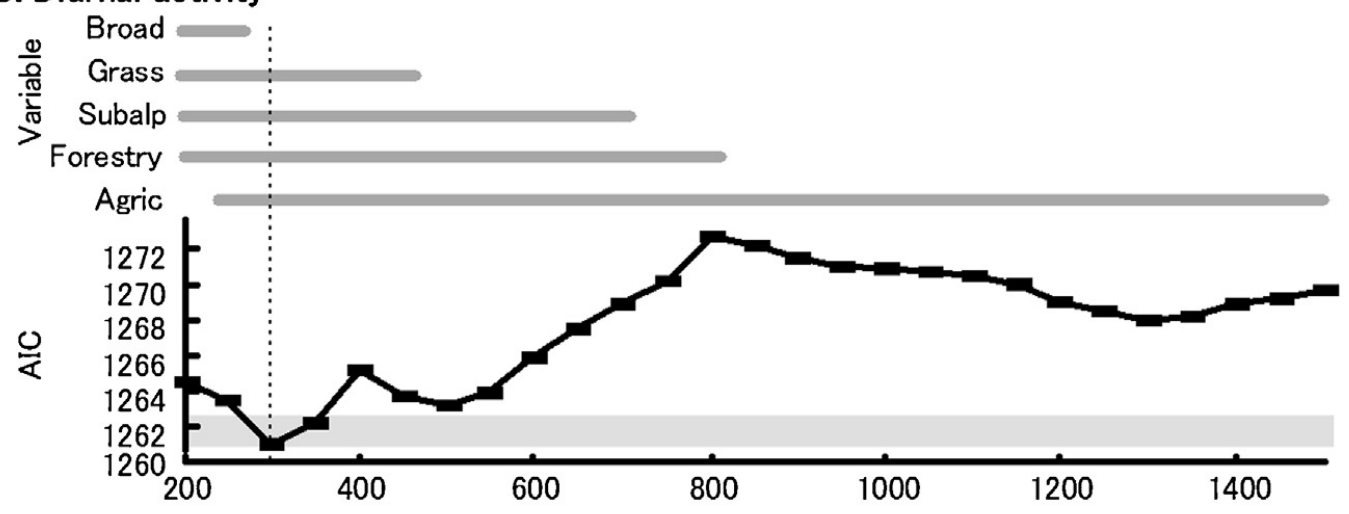

C. Crepuscular activity

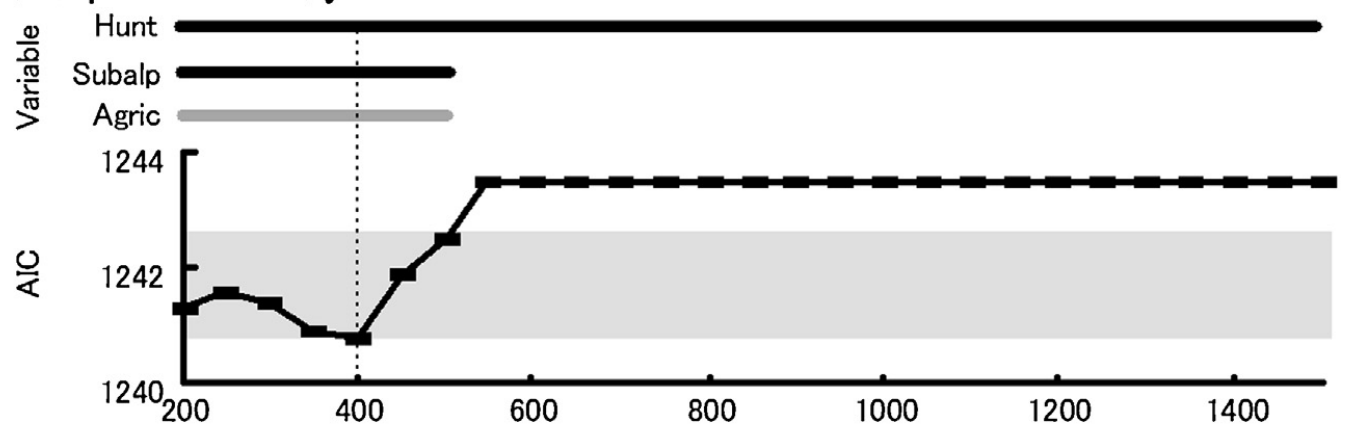

D. Nocturanal activity

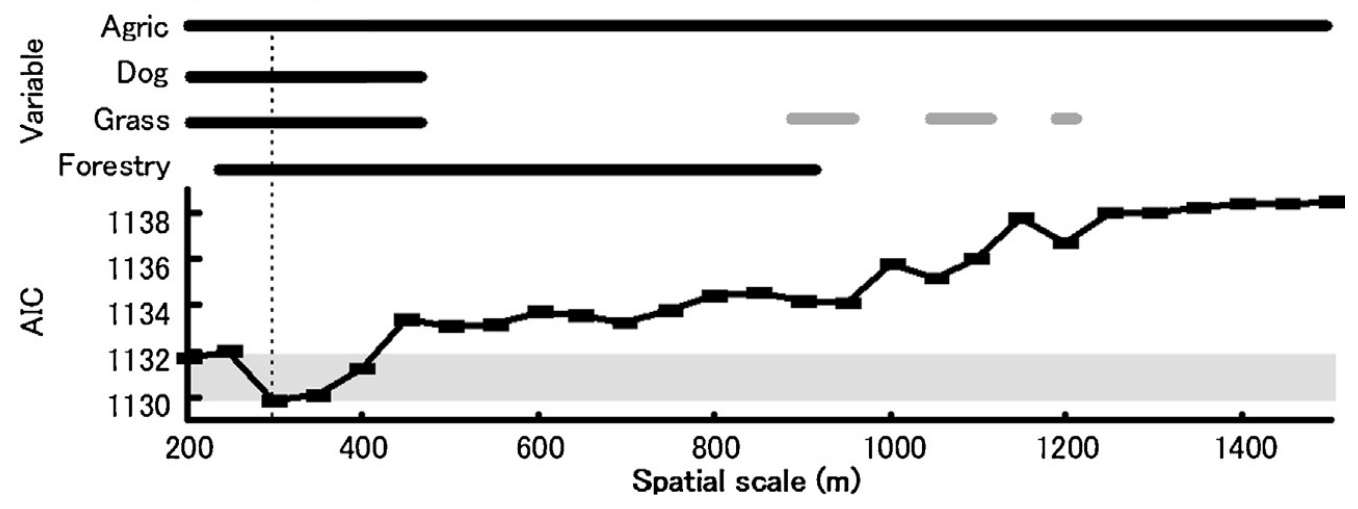

Fig. 2. Selected variables and the smallest Akaike's Information Criterion (AIC) value among models at each spatial scale for deer density (A), diurnal activity (B), crepuscular activity (C) and nocturnal activity (D). Abbreviations of land use types are the same as Fig. 1. Macaque, macaque density; Dog, dog density; Hunt, hunting pressure; black and gray horizontal lines above the graphs indicate positive and negative factors, respectively; a dotted vertical line indicates the effective spatial scale; the gray area indicates the difference of AIC $<2.0$ from the smallest AIC model across the scales. 
Table 2

The effective spatial scales, the selected models and the coefficients of variables at the effective spatial scales.

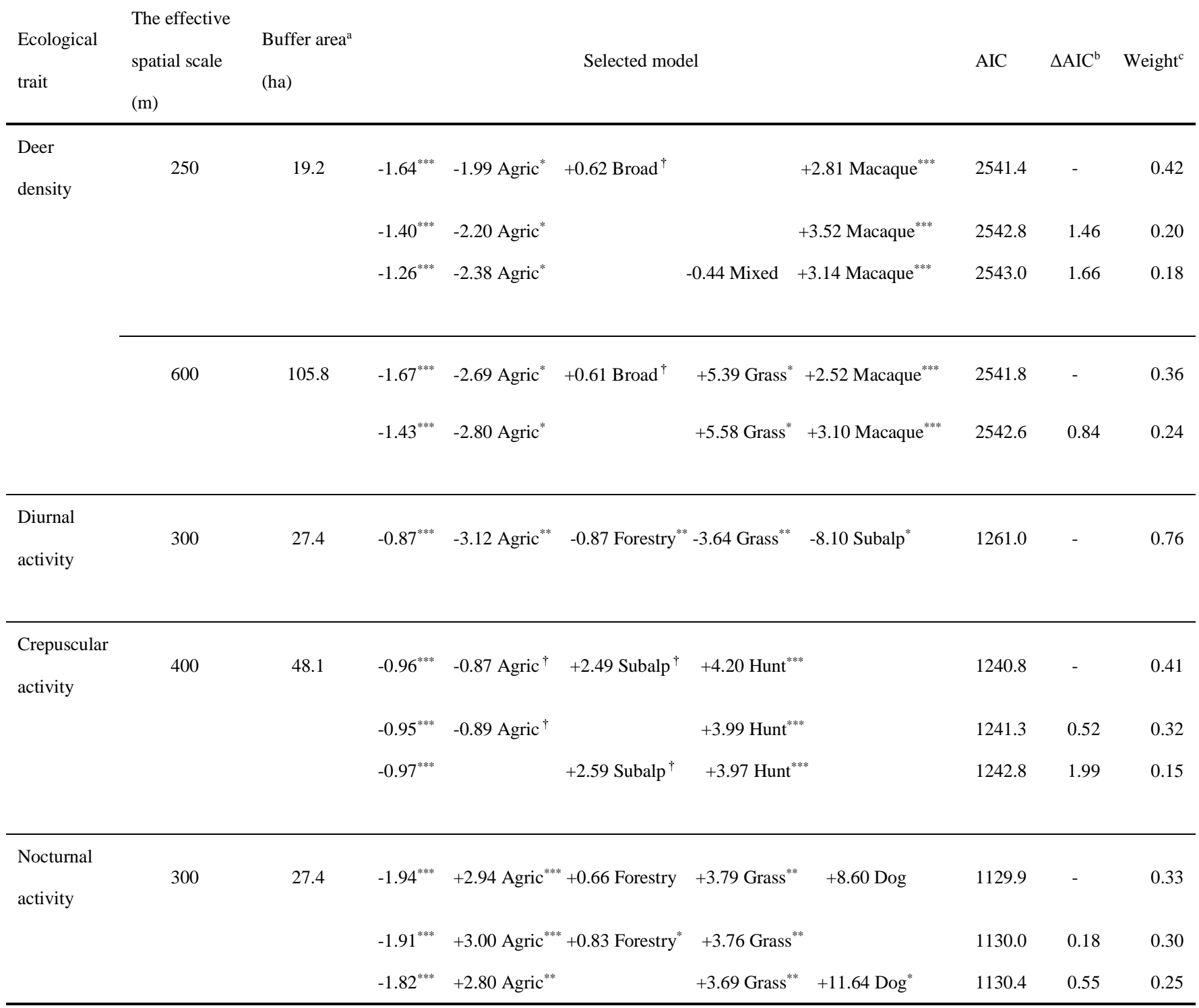

Abbreviations of variables are the same as Fig. 2. $\dagger P<0.1, * P<0.05, * * P<0.01, * * * P<0.001$. $^{\mathrm{a}}$ The mean buffer area excluding sea and rivers at the spatial scale. ${ }^{\mathrm{b}} \Delta \mathrm{AIC}$ within the spatial scale. ${ }^{\mathrm{c}}$ Akaike weight within the spatial scale.

\section{Daily activity patterns}

We obtained 3264 images of deer with time stamps from 348 cameras for analysis of daily activity patterns. Of these, $35 \%, 42 \%$ and $23 \%$ of deer were photographed during daytime (08:00-16:00), crepuscular periods (4:00-8:00 and 16:00-20:00) and nighttime (20:00-04:00), respectively. However, percentages of operating hours of the cameras in these time windows were almost the same (daytime, $33.4 \pm 1.2 \%$ (mean $\pm \mathrm{SD}$ ); crepuscular periods $33.3 \pm 1.5 \%$ and nighttime, $33.3 \pm 0.7 \%$ ). Photographs of dogs were taken by 31 cameras, $72 \%$ of which were taken during the daytime.

For all spatial scales of activities in the three time windows (diurnal, nocturnal and crepuscular), the smallest AIC models were significantly different from the null models 
(likelihood ratio test, for all spatial scales for all activities; $\mathrm{p}<0.01$ ). Five factors were selected for diurnal activity, but the combinations of the factors shifted with spatial scale (Fig. 2B). The effective spatial scale (i.e. the one with the smallest AIC value) was found at $300 \mathrm{~m}$. Agricultural land, forestry area, natural grassland and subalpine vegetation were negative factors for diurnal activity at the effective spatial scale (Table 2). For crepuscular activity, hunting pressure was constantly selected as a positive factor, although two other factors were selected up to the 500-m scale (Fig. 2C). At the effective spatial scale of $400 \mathrm{~m}$, hunting pressure and subalpine vegetation were positive, and agricultural land was a negative factor (Table 2). Four factors were selected for nocturnal activity, and among them agricultural land was consistently selected (Fig. 2D). The effective spatial scale was $300 \mathrm{~m}$ at which agricultural land, forestry area, natural grassland and dog density had positive effects (Table 2).

\section{Discussion}

We predicted that forestry area, hunting pressure and dog density would have negative effects, and agricultural land a positive effect, on deer density (Prediction 1). In fact, our results indicated that forestry area did not have a significant negative effect on deer density (Table 2). However, forestry area may have an indirect negative effect by displacing areas of broad-leaved forest, which had a positive effect on deer density. Contrary to Prediction 1, agricultural land had a negative effect on deer density. Crop raiding by deer has occurred in Yakushima (Agetsuma, 2007), which demonstrates that agricultural lands provide food resources for deer. However, agricultural land tends to have high levels of human activity and a lack of cover. In addition, the local government and individual farmers have been constructing fences around agricultural land to prevent intrusion by deer. These factors may combine to reduce deer density around agricultural land. For hunting pressure, we could not detect a negative effect on deer density. Deer do not always move away from areas where hunting pressure has increased (Kufeld et al., 1988). The low spatial resolution of hunting pressure data in this study may have restricted the detection of a possible negative effect on deer density. However, the effect of hunting was clearly demonstrated in an increase in crepuscular activity. Although some studies have reported negative effects of dogs on ungulate populations (Corti et al., 2010; Silva-Rodriguez and Sieving, 2012), we did not find a negative effect on deer density in Yakushima.

Among natural factors, deer density was affected positively by broad-leaved forest and macaque density, and negatively by mixed forest (Table 2). Deer on this island mainly depend on leaves, fruits and seeds of broad-leaved plants for food (Takatsuki, 1990), which they obtain largely from the forest litter (Agetsuma et al., 2011). In Yakushima, productivity of litter fall and fruits in broad-leaved forests are higher than those in mixed forests or coniferous plantations (Aiba et al., 2007; Hanya and Aiba, 2010; Hanya et al., 2005). Thus, broad-leaved forest should primarily support the deer population in this island. Macaques will supply relatively higher quality food from the tree canopies for deer (Agetsuma et al., 2011). Deer tend to gather where macaques emit food calls (Koda, 2012) to obtain macaque-supplied 
foods efficiently. The positive effect of macaque density on deer density might also be influenced by the fact that both species tend to select similar habitats, as the macaques show a preference for broad-leaved forest where their food resources are abundant (Agetsuma et al., 2015).

The mean buffer areas at the effective spatial scales for daily activity pattern (Table 2) roughly corresponded to the mean annual range size of an individual deer. In accordance with Prediction 2 , the daily activity pattern of deer changed with anthropogenic disturbance. Agricultural land, forestry area and dog density shifted daily activity pattern of deer from diurnal to nocturnal (Table 2). The greater human disturbance and visibility in agricultural land and forestry area may restrict diurnal activity of deer (Mysterud and Ostbye, 1999). In addition, deer also seemed to increase activity during the nighttime when the activity of dogs was relatively low in the study area. Hunting pressure increased deer activity in the crepuscular period. Hunting pressure restricts diurnal activity of deer (Kilgo et al., 1998; Nixon et al., 1991), which may lead them to increase foraging activity just before daylight, and just after daylight to satisfy their hunger quickly.

Although agricultural land was selected as a significant factor for both deer density and daily activity pattern, other types of anthropogenic disturbance (forestry area, hunting pressure and dog density) only affected the daily activity pattern of deer (Table 2), as per Prediction 3. Thus, deer behavior appeared to be more sensitive to various types of disturbance than the population density.

Managing a broad range of habitats and controlling the various kinds of anthropogenic disturbances would promote wildlife conservation. However, in reality, human economic activities and deficiencies in conservation funds make this level of control impossible to achieve. Therefore, we are forced to select types of disturbances and limit the areas that can be managed efficiently and effectively to reduce the impact on wildlife. The types and magnitudes of factors influencing wildlife ecology change with spatial scales (Boyce et al., 2003) as demonstrating in this study (Fig. 2). Thus, it is important to detect the most effective spatial scale to show the greatest effects on wildlife (Agetsuma et al., 2015). We must analyze various factors at appropriate spatial scales to prevent overlooking significant types of anthropogenic disturbances that should be managed.

The protection of natural vegetation (broad-leaved forest and natural grassland) and the restriction of human land use (agricultural land) may be essential for maintaining the deer population size in the study area. The effective spatial scale for deer density suggested that a buffer width of $600 \mathrm{~m}$ will be required for deer habitat management; $750 \mathrm{~m}$ is desirable where the AIC difference from the smallest AIC model across the scales was < 2.0 (Fig. 2A). The mean buffer areas at 750-m scale excluding sea and rivers (162.9 ha) was five to 14 times wider than the mean annual range size of an individual deer. In this study, we could not examine anthropogenic effects on deer ecology at scales greater than1500 m. Additional studies will be needed on larger spatial scales to complete an evaluation of these effects. Macaques were also positively associated with deer density, which suggests that conservation of sympatric species may benefit the conservation of a target species through interspecies interaction. 
Even if a type of anthropogenic disturbance does not have a significant effect on population density, the effect may emerge as the modification of behaviors (Gill et al., 2001) as found in this study. Thus, although most studies to date have focused on only a single aspect of wildlife ecology, such as population density or habitat use (e.g., Anderson et al., 2005; Coulon et al., 2008; Markovchick-Nicholls et al., 2008), detecting the effects on multiple aspects of the ecology is essential.

\section{Acknowledgements}

We are grateful to the Ministry of the Environment, the Yakushima Forest Environment Conservation Center, Kagoshima Prefecture and Yakushima Town for permitting us to conduct this research. WRC of Kyoto University offered us the use of their facilities in Yakushima. We would like to thank Drs. T. Mamabe, M.Suzuki, C. Terada, M. Fujita, and Mr. K. Iwagawa and our friends on Yakushima for supporting our research, Dr. H. Hirakawa of the Forestry and Forest Products Research Institute for technical support for the automatic cameras, Drs. L. Corlatti of University of Natural Resources and Applied Life Sciences, and H. Sugiura and D.A. Hill of Kyoto University for helpful comments on the manuscript. This study was financially supported in part by the Research Project 'Evaluation of Sustainable Forest Use Options and their Perspectives' of Research Institute for Humanity and Nature, by the Research Project 'Conservation and Management Scheme through Long Term Assessment of Natural Ecosystem in the Yakushima World Heritage Area, southern Japan' of The Nature Conservation Society of Japan, by the Global COE Program A06 of Kyoto University, by the Cooperation Research Program of Primate Research Institute, Kyoto University, and by JSPS KAKENHI18380086, 10J01115, 26850106, $15 \mathrm{~K} 07822$.

\section{References}

Agetsuma, N., 2007. Ecological function losses caused by monotonous land use induce crop raiding by wildlife on the island of Yakushima, southern Japan. Ecol. Res. 22, 390-402. Agetsuma, N., Agetsuma-Yanagihara, Y., Takafumi, H., 2005. Ranging patterns of Japanese sika deer in a warm temperate forest of Yakushima. In: Research Institute for Humanity and Nature (Ed.), Annual report of "Sustainability and biodiversity assessment on forest utilization options". Research Institute for Humanity and Nature, Kyoto, pp. 4-5 (in Japanese).

Agetsuma, N., Agetsuma-Yanagihara, Y., Takafumi, H., 2011. Food habits of Japanese deer in an evergreen forest: litter-feeding deer. Mamm. Biol. 76, 201-207.

Agetsuma, N., Koda, R., Tsujino, R., Agetsuma-Yanagihara, Y., 2015. Effective spatial scales for evaluating environmental determinants of population density in Yakushima macaques. Am. J. Primatol. 77, 152-161.

Aiba, S., Hanya, G., Tsujino, R., Takyu, M., Seino, T., Kimura, K., Kitayama, K., 2007. Comparative study of additive basal area of conifers in forest ecosystems along elevational gradients. Ecol. Res. 22, 439-450. 
Anderson, D.P., Turner, M.G., Forester, J.D., Zhu, J., Boyce, M.S., Beyer, H., Stowell, L., 2005. Scale dependent summer resource selection by reintroduced elk in Wisconsin, USA. J.

Wildl. Manage. 69, 298-310.

Arnold, T.W., 2010. Uninformative parameters and model selection using Akaike's

Information Criterion. J. Wildl. Manage. 74, 1175-1178.

Baillie, J.E.M., Hilton-Taylor, C., Stuart, S.N., 2004. 2004 IUCN Red List of Threatened

Species: A Global Species Assessment. IUCN, Gland/Cambridge.

Barton, K., 2015. Multi-Model Inference, Available at: http://CRAN.R-

project.org/package=MuMIn.

Blom, A., Van Zalinge, R., Mbea, E., Heitkonig, I.M.A., Prins, H.H.T., 2004. Human impact on wildlife populations within a protected Central African forest. Afr. J. Ecol. 42, 23-31.

Boyce, M.S., Mao, J.S., Merrill, E.H., Fortin, D., Turner, M.G., Fryxell, J., Turchin, P., 2003.

Scale and heterogeneity in habitat selection by elk in Yellowstone National Park.

Ecoscience 10, 421-431.

Burnham, K.P., Anderson, D.R., 2002. Model Selection and Multimodel Inference: A Practical Information-theoretic Approach, 2nd edition. Springer, New York.

Corti, P., Wittmer, H.U., Festa-Bianchet, M., 2010. Dynamics of a small population of endangered huemul deer (Hippocamelus bisulcus) in Chilean Patagonia. J. Mammal. 91, 690-697.

Coulon, A., Morellet, N., Goulard, M., Cargnelutti, B., Angibault, J., Hewison, A.J.M., 2008. Inferring the effects of landscape structure on roe deer (Capreolus capreolus) movements using a step selection function. Landsc. Ecol. 23, 603-614.

Dormann, C.F., Elith, J., Bacher, S., Buchmann, C., Carl, G., Carré, G., Marquéz, J.R.G.,Gruber, B., Lafourcade, B., Leitão, P.J., Münkemüller, T., McClean, C., Osborne,P.E., Reineking, B., Schröder, B., Skidmore, A.K., Zurell, D., Lautenbach, S., 2013. Collinearity: a review of methods to deal with it and a simulation study evaluating their performance. Ecography 36, 27-46.

Environment Agency, 1984. Nature of Yakushima. The Nature Conservation Society of Japan, Tokyo (in Japanese).

Fletcher, R.J.J., Hutto, R.L., 2008. Partitioning the multi-scale effects of human activity on the occurrence of riparian forest birds. Landsc. Ecol. 23, 727-739.

Gill, R.M.A., Johnson, A.L., Francis, A., Hiscocks, K., Peace, A.J., 1996. Changes in roe deer (Capreolus capreolus L.) population density in response to forest habitat succession. For. Ecol. Manage. 88, 31-41.

Gill, J.A., Norris, K., Sutherland, W.J., 2001. Why behavioural responses may not reflect the population consequences of human disturbance. Biol. Conserv. 97,265-268.

Hanya, G., Aiba, S., 2010. Fruit fall in five warm- and cool-temperate forests in Yakushima, Japan. For. Stud. China 12, 184-192.

Hanya, G., Zamma, K., Hayaishi, S., Yoshihiro, S., Tsuiya, Y., Sugaya, S., Kanaoka, M.M., Hayakawa, S., Takahata, Y., 2005. Comparisons of food availability and group density of Japanese macaques in primary, naturally regenerated, and plantation forests. Am. J.

Primatol. 66, 245-262. 
Hill, D.A., Agetsuma, N., Suzuki, S., 1994. Preliminary survey of group density of Macaca fuscata yakui in relation to logging history at seven sites in Yakushima, Japan. Primate Res. 10, 85-93.

Hockin, D., Ounsted, M., Gorman, M., Hill, D., Keller, V., Barker, M.A., 1992. Examination of the effects of disturbance on birds with reference to its importance in ecological assessments. J. Environ. Manage. 36, 253-286.

Hurlbert, S.H., 1984. Pseudoreplication and the design of ecological field experiments. Ecol. Monogr. 54, 187-211.

Izawa, K., Kasuya, T., Kawamichi, T., 1996. The Encyclopedia of Animals in Japan. Vol.2: Mammal II. Heibonsha, Tokyo (in Japanese).

Kamler, J.F., Jedrzejewska, B., Jedrzejewski, W., 2007. Activity patterns of red deer in Bialowieza National Park, Poland. J. Mammal. 88, 508-514.

Kilgo, J.C., Labisky, R.F., Fritzen, D.E., 1998. Influences of hunting on the behavior of whitetailed deer: implications for conservation of the Florida Panther. Conserv. Biol. 12, 13591364.

Kilpatrick, H.J., Lima, K.K., 1999. Effects of archery hunting on movement and activity of female white-tailed deer in an urban landscape. Wildl. Soc. Bull. 27, 433-440.

Koda, H., 2012. Possible use of hetero specific food-associated calls of macaques by sika deer for foraging efficiency. Behav. Process. 91, 30-34.

Koda, R., Agetsuma, N., Tsujino, R., Agetsuma-Yanagihara, Y., Mamabe, T., 2010. Distribution and population size of Yaku sika deer in the island of Yakushima estimated by the fecal pellet group count method. In: The Nature Conservation Society of Japan (Ed.), Conservation and management scheme through long term assessment of natural ecosystem in the Yakushima World Heritage Area, southern Japan. Ministry of the Environment, Government of Japan, Kumamoto, pp.115-122 (in Japanese).

Koda, R., Agetsuma, N., Agetsuma-Yanagihara, Y., Tsujino, R., Fujita, N., 2011. A proposal of the method of deer density estimate without fecal decomposition rate: a case study of fecal accumulation rate technique in Japan. Ecol. Res. 26, 227-231.

Kufeld, R.C., Bowden, D.C., Schrupp, D.L., 1988. Influence of hunting on movements of female mule deer. J. Range Manage. 41, 70-72.

Markovchick-Nicholls, L., Regan, H.M., Deutschman, D.H., Widyanata, A., Martin,B., Noreke, L., Hunt, T.A., 2008. Relationships between human disturbance and wildlife land use in urban habitat fragments. Conserv. Biol. 22, 99-109.

Miller, S.G., Knight, R.L., Miller, C.K., 2001. Wildlife responses to pedestrians and dogs. Wildl. Soc. Bull. 29, 124-132.

Mysterud, A., Ostbye, E., 1999. Cover as a habitat element for temperate ungulates: effects on habitat selection and demography. Wildl. Soc. Bull. 27, 385-394.

Nixon, C.M.L.P., Hansen, L.P., Brewer, P.A., Chelsvig, J.E., 1991. Ecology of white-tailed deer in an intensively farmed region of Illinois. Wildl. Monogr. 118, 1-77.

Ohsawa, M., Tagawa, H., Yamagiwa, J., 2006. World Heritage, Yakushima. Asakura Publishing, Tokyo (in Japanese).

Okabe, F., Agetsuma, N., 2007. Habitat use by introduced raccoons and native raccoon dogs in 
a deciduous forest of Japan. J. Mammal. 88, 1090-1097.

Presley, S.J., Willing, M.R., Castro-Arellano, I., Weaver, S.C., 2009. Effects of habitat conversion on temporal activity patterns of phyllostomid bats in lowland Amazonian rain forest. J. Mammal. 90, 210-221.

R Core Team, 2015. R: A Language and Environment for Statistical Computing. R Foundation for Statistical Computing, Vienna, Austria.

Riley, S.P.D., Hadidian, J., Manski, D.A., 1998. Population density, survival, and rabies in raccoons in an urban national park. Can. J. Zool. 76, 1153-1164.

Rovero, F., Marshall, A.R., 2009. Camera trapping photographic rate as an index of density in forest ungulates. J. Appl. Ecol. 46, 1011-1017.

Sergent, M., Mathieu, D., Phan-Tan-Luu, R., Drava, G., 1995. Correct and incorrect use of multilinear regression. Chemom. Intellig. Lab. Syst. 27, 153-162.

Silva-Rodriguez, E.A., Sieving, K.E., 2012. Domestic dogs shape the landscape-scale distribution of a threatened forest ungulate. Biol. Conserv. 150, 103-110.

Skaug, H., Fournier, D., Bolker, B., Magnusson, A., Nielsen, A., 2014. Generalized linear mixed models using AD model builder, Available at http://glmmadmb.r-forge.r-project.org.

Sweeney, J.R., Marchinton, R.L., Sweeney, J.M., 1971. Responses of radio-monitored whitetailed deer chased by hunting dogs. J. Wildl. Manage. 35, 707-716.

Tagawa, H., 1994. Natural World Heritage, Yakushima. Japan Broadcast Publishing, Tokyo (in Japanese).

Takatsuki, S., 1990. Summer dietary composition of sika deer on Yakushima Island, southern Japan. Ecol. Res. 5, 253-260.

Tsujino, R., Agetsuma-Yanagihara, Y., 2006. Alien mammals, raccoon dog, feral dog, feral cat, and feral goat in western and north-western part of lowland forest on Yakushima Island in Kagoshima Prefecture. Jpn. J. Conserv. Ecol. 11, 167-171 (in Japanese).

Willig, M.R., Presley, S.J., Bloch, C.P., Hice, C.L., Yanoviak, S.P., Díaz, M.M., Chauca, L.A.,Pacheco, V., Weaver, S.C., 2007. Phyllostomid bats of lowland Amazonia: effects of habitat alteration on abundance. Biotropica 39, 737-746.

Zweifel-Schielly, B., Kreuzer, M., Ewald, K.C., Suter, W., 2009. Habitat selection by an Alpine ungulate: the significance of forage characteristics varies with scale and season.

Ecography 32, 103-113. 